\title{
Questão Habitacional e Serviço Social: aproximação ao debate
}

\author{
Housing Issue and Social Work: approach to debate
}

\author{
Flavia Cavalcante Nicolis de Medeiros*
}

\begin{abstract}
Resumo:
Este artigo discute o processo de urbanização capitalista nos países periféricos, como o Brasil, suas particularidades e contradições. Além disso, é apresentada a configuração da questão habitacional como uma das expressões da questão social, objeto de intervenção do Serviço Social, relacionando-a ao debate acerca do direito à cidade e à moradia na atualidade. A metodologia utilizada consiste numa pesquisa bibliográfica e uma análise crítica do tema. $O$ artigo conclui que o debate crítico sobre o uso e a ocupação do solo urbano e a função social da propriedade é fundamental para subsidiar ações concretas visando legitimar e efetivar o direito à cidade e à moradia.
\end{abstract}

Palavras-chave: Questão Habitacional. Serviço Social. Direito à Cidade. Direito à Moradia.

\begin{abstract}
:
This article discusses the process of capitalist urbanization in peripheral countries, such as Brazil, its peculiarities and contradictions. In addition, the configuration of the housing issue is presented as one of the expressions of the social issue, object of intervention by Social Work, relating it to the debate about the right to the city and to housing nowadays. The main conclusion of the the paper is that the critical debate on the use and occupation of urban land and the social function of property is fundamental to subsidize concrete actions aiming at legitimizing and make the rights to the city and to housing.
\end{abstract}

Keywords: Housing Issue. Social Work. Right to the City. Right to Housing.

\footnotetext{
* Doutorado em Serviço Social pela Universidade Federal do Rio de Janeiro (UFRJ/2006); Mestrado em Serviço Social pela Universidade Federal do Rio de Janeiro (UFRJ/1996); Especialização em Docência do Ensino Superior pelas Faculdades Integradas de Jacarepaguá (FIJ/ RJ/ 2007); Graduação em Serviço Social pela Universidade Federal de Juiz de Fora (UFJF/1992). Docente do Curso de Graduação em Serviço Social nas Faculdades Integradas Espírita em Curitiba, no Paraná (FIES/2010) e no Centro Universitário Autônomo do Brasil (UniBrasil/ 2011- 2020).
} 


\section{Introdução}

As tragédias que atingem direta ou indiretamente os moradores dos centros urbanos (enchentes, deslizamentos de terra, crescimento acelerado das favelas, violência, altos índices de acidentes de tráfego, poluição do ar e dos rios, epidemias, dentre outros) fazem parte do seu cotidiano, embora, muitas vezes, não tenham consciência da relação entre todos esses fatos que se situa na base do processo do crescimento urbano no Brasil. Assim, torna-se necessário desvendar as especificidades da sociedade brasileira, bem como ampliar a consciência acerca do processo de crescimento urbano visando identificar os interesses conflitantes presentes na luta pelo espaço na cidade. Deve-se destacar que o cenário urbano em nosso país é resultante de determinadas relações sociais que excluem grande parcela da população do direito à moradia e à cidade. Ademais, na trajetória histórica da produção das cidades e da moradia no Brasil há dois fatores relacionados - a apropriação da terra e a apropriação da riqueza gerada pelo trabalho - que configuram as características que as cidades assumiram, sobretudo, a partir do século XIX e permanecem na atualidade (MARICATO, 2010).

Nesse sentido, há distintos interesses envolvidos na luta pelo espaço na cidade e sua articulação com o Estado na elaboração e gestão da política de habitação e da política urbana, como o poder público, os proprietários, o mercado imobiliário, as construtoras, os movimentos e organizações sociais, bem como, a própria população de baixa renda que não tem acesso à moradia digna e adequada, sendo obrigada a viver em condições precárias e, muitas vezes, de risco. Estes sujeitos diversos influenciam a produção do espaço urbano e a intervenção do poder público no enfrentamento da questão habitacional estando diretamente relacionados aos contextos históricos, sociopolíticos e econômicos, tanto ao nível nacional como internacional (ibidem).

Portanto, a questão habitacional se configura como uma das expressões da questão Social (IAMAMOTO, 1998) e se constitui um desafio contemporâneo para a categoria de assistentes sociais que lidam no seu cotidiano com as diversas demandas dos (as) usuários (as) na perspectiva da defesa das políticas públicas e efetivação de direitos de cidadania, dentre eles, o acesso à moradia digna que está intimamente relacionado ao direito à cidade, conforme preconizam a Constituição Federal de 1988, o Estatuto da Cidade (2001) e o Conselho Federal de Serviço Social (CFESS, 2016). 
Cabe explicitar, ainda, que o objetivo deste artigo consiste em discutir o processo de urbanização capitalista nos países periféricos, como o Brasil, suas particularidades e contradições, apresentando a estruturação da questão habitacional como uma das expressões da questão social, objeto de intervenção do Serviço Social, vinculando-a ao debate sobre o direito à cidade e à moradia na contemporaneidade. No que se refere à metodologia empregada, esta consiste em uma pesquisa bibliográfica associada à uma análise crítica dos desafios apontados.

Este artigo foi estruturado de um debate mais amplo do tema para um mais específico, visando contribuir com a relação teoria e prática profissional. Neste sentido, a próxima seção trata do espaço urbano capitalista ocidental, suas características, especificidades e contradições e, na sequência, aborda-se o arcabouço legal do direito à moradia, levando em consideração as suas conquistas e seus desafios na efetivação desse direito. Aprofundando-se nas particularidades da atuação profissional do(a) assistente social, a seção subsequente apresenta uma reflexão sobre a questão habitacional e a intervenção do Serviço Social. As duas últimas seções do artigo versam sobre as considerações finais e as referências.

\section{Espaço Urbano: particularidades e contradições}

O espaço urbano capitalista se configura inicialmente como um conjunto de distintos usos da terra justapostos entre si. Tais usos da terra definem áreas como o centro da cidade, local de concentração de atividades comerciais, de serviços e de gestão; também áreas industriais, mais afastadas; áreas residenciais diversificadas em termos de forma e conteúdo social, de lazer e, entre outras, aquelas de reserva para futura expansão (CORREA, 1995).

Deve-se salientar que o espaço urbano é, ao mesmo tempo, fragmentado e articulado, pois cada uma de suas partes mantém relações espaciais com as demais. Tais relações se configuram concretamente através de fluxos de veículos e de pessoas associados às operações de carga e descarga de mercadorias, aos deslocamentos cotidianos entre as áreas residenciais e de trabalho, aos deslocamentos menos frequentes para compras no centro da cidade ou nas lojas do bairro, para lazer, dentre outras (ibidem).

Portanto, o espaço urbano capitalista se configura como profundamente desigual devido aos interesses das distintas classes sociais. "O espaço da cidade é também o objeto e 
o cenário das lutas sociais, pois estas visam, afinal de contas, o direito à cidade, à cidadania plena e igual para todos" (CORREA, 1995, p. 09).

A condição das cidades periféricas no capitalismo global está intimamente relacionada à configuração da cidade capitalista e sua especificidade na periferia do capitalismo. Assim, torna-se necessário considerar as assimetrias existentes entre os países do mundo capitalista. Nesse quadro, encontra-se a crise urbana em nosso país que se expressa claramente a partir das manifestações de julho de 2013, tendo suas raízes no passado recente, nas chamadas décadas perdidas (anos 1980 e 1990) quando as metrópoles brasileiras sofreram o impacto da reestruturação produtiva do capitalismo ou globalização neoliberal (MARICATO, 2015).

No que concerne à cidade deve-se ressaltar que esta é uma mercadoria, assim como todos os elementos que a constituem (edifícios, postes, mobiliário urbano, redes de infraestrutura, pontes, viadutos, etc.), pois se situa num país capitalista onde a generalização da mercadoria se apropria das relações sociais. Contudo, estas são mercadorias especiais e é relevante fazer essa distinção porque há capitais que entram na produção de tudo que precisamos para viver e capitais específicos que entram na produção da cidade. "A maior parte dessa especificidade se dá pela ligação com o solo urbano. Essa ligação dá à mercadoria edifício, que pode ter o uso habitacional, por exemplo, uma especificidade dentro do capitalismo" (MARICATO, 2015, p. 11-12).

Deve-se salientar ainda que a localização na cidade interfere diretamente no valor dessa mercadoria especial, a moradia, que se denomina como renda imobiliária. Ademais, o preço da moradia pode ser elevado também pelas características de seu entorno, tais como a existência de Shoppings centers, jardins, pavimentação, iluminação pública, oferta de serviços como coleta de lixo, entre outros, são atributos que valorizam os imóveis (ibidem).

Assim sendo, os segmentos sociais de maior poder aquisitivo vão ocupar as áreas com melhor localização e dotadas de infraestrutura urbana, enquanto a população de baixa renda vai ocupar as áreas mais afastadas, em geral, dotadas de pouca ou nenhuma infraestrutura e serviços (saneamento básico, iluminação pública, calçamento, coleta de lixo, transporte público) (MARICATO, 2015; NICOLIS, 1996).

Para compreender esse quadro, torna-se necessário abordar a produção do espaço urbano que é responsável pela grande maioria dos problemas da cidade, como a segregação 
socioespacial. Como referido, a localização na cidade tem um preço e somente as pessoas que têm poder aquisitivo podem pagar pelas moradias com boa localização e dotadas de infraestrutura e serviços. Cabe então indagar sobre o significado do direito à cidade nesse quadro complexo e desigual.

\begin{abstract}
Nos programas habitacionais o direito à cidade é traduzido como o direito à água, ao esgoto, à energia elétrica, etc. Não, não é só isso. Henri Lefebvre em várias obras, defende até o direito à 'festa' representada pela vida urbana: os cafés, as praças, os jardins, etc. Isso tudo tem a ver com localização e seu preço. Existe uma luta surda pelas localizações na cidade e uma disputa acirrada pelo fundo público. Ela diz respeito ao investimento público que tem grande impacto sobre os preços imobiliários (MARICATO, 2015, p.12).
\end{abstract}

Portanto, é fundamental considerar os processos de produção da cidade, de espraiamento da ocupação do solo, também o urbanismo do espetáculo, os impactos dos megaeventos (Copa do Mundo, Jogos Olímpicos), e a legislação urbana, pois, todos esses processos podem definir a valorização ou desvalorização de imóveis.

Nesse quadro, é necessário considerar os agentes que controlam a produção do espaço urbano, isto é, quem controla o crescimento da cidade, a ocupação do solo, os investimentos - os promotores, construtores financiadores, proprietários de terra, e o papel do Estado nos âmbitos local, estadual e nacional (CORREA, 1995; MARICATO, 2015).

O Brasil se caracteriza por uma industrialização tardia com baixos salários e por isso corresponde a uma urbanização dos baixos salários. Isso significa que uma parcela da população trabalhadora não possui renda suficiente para comprar uma casa no mercado imobiliário formal capitalista, o que leva grande parte dos trabalhadores assalariados a construir sua própria casa nos finais de semana. Mesmo sendo uma força de trabalho com carteira assinada no mercado formal, tal situação conduz à moradia informal na cidade (MARICATO, 2015).

Assim, com regras detalhadas, um poderoso aparato legal, burocracia excessiva, convive-se com uma radical flexibilidade na realidade da ocupação do solo. No capitalismo periférico, no contexto patrimonialista, ocorre a privatização do Estado, as leis avançadas não são aplicadas ou quando são aplicadas atendem prioritariamente aos interesses capitalistas do mercado imobiliário. Nesse cenário ocorre a universalização da política do favor, o distanciamento entre o discurso, a prática e a realidade (Idem). 
As ocupações menos organizadas, seja na favela ou no loteamento ilegal também fazem parte do processo de construção da cidade que é próprio de um país que não é do capitalismo central. Essa situação se alastra nas cidades brasileiras, sobretudo, nas periferias das metrópoles localizadas nas regiões norte e nordeste. Como os salários da maioria da população são baixos e insuficientes para suprir suas necessidades, aliada ao desemprego, altos aluguéis e especulação imobiliária, ocorre a ocupação irregular de áreas mais afastadas e/ ou degradadas, com pouca ou nenhuma infraestrutura. O significado desse processo é que o Estado não tem controle sobre o uso e ocupação do solo, bem como que o urbanismo formal, as leis do parcelamento do solo, os planos diretores, desconhecem muito dessa realidade (ibidem).

Além disso, Maricato (2015) menciona as favelas de palafitas em áreas de mangues como na Baixada Santista. Essas áreas são protegidas por lei federal, pois são áreas incubadoras da vida marinha. Existem áreas de mangues ocupadas em litorais de todo o país e, aparentemente, as pessoas poderiam ficar nesses locais. O mesmo não acontece em imóveis vazios no centro da cidade, pois se houver a ocupação irregular nessa localidade as pessoas certamente serão expulsas. Isso ocorre porque

\footnotetext{
não é a lei, norma jurídica, que conduz o controle do uso e ocupação do espaço, é lei de mercado, porque terra ou imóvel no centro da cidade tem valor de mercado e no mangue não tem. Não é difícil mostrar que é mais importante proteger uma área de mangue do que proteger um imóvel vazio no centro da cidade que aliás não está cumprindo sua função social (Maricato, 2015, p. 15).
}

As raízes da crise urbana no Brasil estão no seu processo de urbanização que ocorreu no século XX muito rapidamente. No aspecto econômico o país cresceu muito da década de 1940 a de 1980 (mais de 7\% a.a.), mantendo a desigualdade social. Um grande contingente de pessoas do campo vinha para as cidades durante esse período na expectativa de se beneficiar de algum modo desse crescimento econômico (MARICATO, 2015).

Nesse período, a reestruturação produtiva (ou globalização) atingiu o nosso país impactando sua herança colonial. Isso significa que a globalização, dominada pelo ideário neoliberal, atingiu uma realidade que não era plenamente moderna visando a contenção de investimentos em políticas sociais; a privatização de serviços públicos; a restrição de investimentos em serviços públicos (ibidem). 
Tal globalização neoliberal também trouxe um modo de uso e ocupação do espaço em nosso país inserindo-o numa economia globalizada. Nessa direção, a autora assevera que as fórmulas urbanísticas disseminadas pelo neoliberalismo transformaram as cidades em um grande negócio: privatizações; desregulamentações; cidade empreendedora; competição entre cidades; plano estratégico, parcerias público-privadas; operações urbanas.

Por outro lado, a autora afirma que no mencionado período das décadas perdidas (1980/1990) no Brasil, a academia foi relevante porque suas pesquisas deram visibilidade à cidade real e ao modo como os trabalhadores vivem. Isso é importante poque "a cidade capitalista se alimenta sempre do simulacro da realidade, de uma representação ideológica da realidade. A representação ideológica da realidade, da cidade, é o cartão postal, então a periferia é desconhecida" (ibidem). Do mesmo modo, as prefeituras se destacaram através de governos locais inovadores e democráticos. Também surgiram novos movimentos sociais e sindicais, novos partidos, novas centrais sindicais, novas leis.

Em São Paulo, nesse período, na gestão de Luiza Erundina, Maricato esteve na Secretaria de Habitação e Desenvolvimento (1989-1991) e o debate girava em torno de inovar a gestão para inverter prioridades e focar nas áreas degradadas na urbanização de favelas, nas áreas de riscos de enchentes, desmoronamento, epidemias, etc. Além disso, o trabalho na construção de novas moradias de modo participativo e pelo direito à arquitetura.

\footnotetext{
Muitos escritórios técnicos de arquitetos, engenheiros e advogados se formaram para dar assessoria aos movimentos sociais. Conquistamos novas leis visando a justiça urbana, inovações em projetos e obras de infraestrutura urbana. A iniciativa desse período que mais ganhou prestígio no mundo todo foi o Orçamento Participativo praticado em Porto Alegre (MARICATO, 2015, p.17).
}

A autora destaca que tudo isso foi realizado num período de poucos recursos, no Governo de Fernando Henrique Cardoso, o que é interessante, pois "o Fundo Monetário Internacional (FMI) ficava com as quatro patas em cima do Brasil controlando os orçamentos" (ibidem). A autora também salienta os avanços advindos do Movimento de Reforma Urbana: o Estatuto da Cidade; a criação do Ministério das Cidades; as Conferências Nacionais das Cidades; o Programa Nacional de Regularização Fundiária; o Conselho Nacional das Cidades; a Lei de Consórcios Públicos; o Plano Diretor Participativo; a Lei do Saneamento; a Lei da Mobilidade Urbana; a Lei sobre Resíduos Sólidos, que configuram todo um arcabouço novo e relevante em nosso país (ibidem). 
Na sequência, em 2007, foram retomados os investimentos com o PAC (Programa de Aceleração do Crescimento), sendo que a urbanização de áreas degradadas e o saneamento nas cidades foram advindos dos recursos desse programa.

No ano de 2009 foi instituído o Programa Minha Casa, Minha Vida (PMCMV) e o PAC 2, onde o Estado retomava os investimentos sobre o território e as cidades.

\begin{abstract}
Um novo projeto desenvolvimentista (ou neodesenvolvimentista) garantiu a mais baixa taxa de desemprego da história recente: subsídios para habitação social; retomada do investimento de habitação e saneamento; incentivos à indústria automobilística (desonerações fiscais) e à construção civil. O Governo Federal tentava fazer frente à crise internacional (MARICATO, 2015, p. 18).
\end{abstract}

Todavia, a autora argumenta que apesar de todos esses avanços expressos na ampliação de recursos de subsídios para moradia social, acrescidos do novo quadro legal e de novas instituições, essa retomada dos investimentos trouxe, contraditoriamente, a perda de controle social sobre o espaço urbano, pois os capitais tomaram conta da cidade impondo seus interesses particularistas sob a lógica mercadológica.

Sendo assim, se evidencia um paradoxo nesse quadro na medida em que os investimentos para as políticas urbanas resultaram em distorções que afetaram muito os trabalhadores assalariados. "Os preços dos imóveis no Rio de Janeiro, São Paulo e Belo Horizonte cresceram mais de $200 \%$ o metro quadrado. O capital imobiliário e o capital de construção tomam comando sobre as cidades e sobre, evidentemente, o solo urbano" (MARICATO, 2015, p. 18). A partir desses processos ocorreram despejos violentos de favelas e a periferia pobre avançava. A segregação se reafirmava e o espraiamento urbano se ampliava devido ao aumento demasiado dos aluguéis expulsando muitas pessoas para as periferias da cidade (ibidem).

A autora afirma ainda que os incentivos à indústria automobilística (com a desoneração de impostos) realizados pelo governo federal contribuíram para a manutenção do desemprego em níveis baixos, mas as cidades pagaram um preço alto.

O número de carros dobrou em 10 anos nas cidades brasileiras e triplicou o número de motos. Com isso, ocorreu o boom automobilístico e a resultante foi o aumento do deslocamento das pessoas na cidade, por exemplo, em São Paulo o tempo médio de viagem é de mais de 2 horas. Assim, houve um impacto sobre os trabalhadores, já que mais de $70 \%$ dos empregos está na capital e grande parte desses trabalhadores, sobretudo empregadas domésticas, moram fora da capital [...]. (MARICATO, 2015, p. 18) 
A crise de mobilidade tem a ver não apenas com o padrão do transporte, mas com o uso e a ocupação do solo, numa cidade que é muito mais dispersa há muita dificuldade de mobilidade. A mobilidade é muito mais cara devido à especulação em relação à terra (MARICATO, 2015, p. 13).

A despeito da retomada dos investimentos no saneamento e na habitação, da melhoria na distribuição de renda e no aumento da participação social nos conselhos, o impasse da política urbana persiste devido, especialmente, à manutenção do padrão fundiário e da mobilidade excludente. Essas condições estão vinculadas - o uso e ocupação do solo e a mobilidade -, isso porque somente se houver controle desses processos por parte do Estado será viável reverter o quadro de segregação socioespacial, a precariedade, a ausência ou distanciamento dos equipamentos públicos, o predomínio da especulação imobiliária e da lógica do mercado na produção da cidade. O quadro atual é bem complexo e desafiador, pois, "mais do que nunca a cidade é dominada pelas forças do capital em associação com a grande mídia e em relação com o financiamento de campanhas eleitorais" (MARICATO, 2015, p. 19).

A autora assevera que, nesse contexto, a centralidade da terra e a função social da propriedade - preconizadas na Constituição Federal de 1988, no Estatuto da Cidade (2001) e na Reforma Urbana - foram esquecidas e houve a institucionalização dos movimentos sociais. Por outro lado, há leis, planos, experiência e conhecimento, mas, falta concretizar tudo isso no espaço urbano, este é o grande desafio na contemporaneidade para todos os que atuam na perspectiva da efetivação do direito à cidade e, por conseguinte, do direito à moradia.

Após abordar o debate sobre o espaço urbano, suas particularidades históricas e contradições, a seguir será tratado, de modo sucinto, o arcabouço legal (internacional e nacional) que sustenta o direito à moradia devido à sua relevância tanto na reflexão quanto na intervenção profissional do (a) assistente social e profissionais afins.

\section{Fundamentação legal do direito à moradia: avanços e desafios}

O direito à moradia está diretamente vinculado à dignidade da pessoa humana, fundamento do Estado brasileiro. Este direito inclui o direito de ocupar um lugar no espaço e, também, o direito às condições que tornam este espaço um local adequado de moradia visando constituir a existência humana (PANSIERI, 2012). 
Assim, torna-se necessário resgatar historicamente como se constituiu o direito à moradia no seu aspecto legal, bem como seu viés ético e político, visando subsidiar reflexões e intervenções voltadas à legitimação e efetivação desse direito básico na atualidade.

Em 1948, com a Declaração Universal do Direitos Humanos da Organização das Nações Unidas (ONU) surgiu, pela primeira vez, o reconhecimento internacional dos chamados direitos econômicos, sociais e culturais, dentre os quais, o direito à moradia, com o seguinte dispositivo:

Todos têm direito ao repouso e ao lazer, bem como a um padrão de vida capaz de assegurar a si e à sua família saúde e bem-estar, inclusive alimentação, vestuário, habitação, cuidados médicos e serviços sociais indispensáveis, o direito à segurança em caso de desemprego, doença invalidez, viuvez, velhice, ou outros casos de perda dos meios de subsistência e circunstâncias fora de seu controle (ONU citada por PANSIERI, 2012, p. 37).

A partir desse período a moradia ou habitação passou a constar em diversos outros Tratados Internacionais:

a) Pacto Internacional de Direitos Sociais, Econômicos e Culturais (1966), da ONU, ratificado pelo Brasil, que trazia em seu art. 11: "Os Estados signatários do presente pacto reconhecem o direito de toda pessoa a um nível de vida adequado para si próprio e para sua família, inclusive alimentação, vestimenta e moradia adequados, assim como uma contínua melhoria de suas condições de vida".

b) Declaração de Vancouver sobre Assentamentos Humanos - HABITAT I - (1976) realizado no Canadá, no qual foi assegurado o direito à moradia adequada como um direito básico da pessoa humana.

c) Agenda HABITAT II (1996) - resultado de uma Conferência da ONU realizada em Stambul, na Turquia, sendo considerado um dos mais completos documentos sobre a matéria (e do qual o Brasil também é signatário), além de reafirmar a moradia como um direito de realização progressiva, com a remissão a pactos internacionais anteriores, esse último documento trouxe a previsão detalhada sobre o conteúdo, a extensão e as responsabilidades dos Estados signatários no que se refere à moradia adequada.

Deve-se salientar que cerca de 155 países reconhecem o direito à moradia em suas respectivas Constituições. Apesar disso, tanto a sociedade, em geral, como os operadores do 
direito, se deparam com a frustração advinda da constatação de que esses direitos não têm conseguido atingir níveis satisfatórios de efetividade (PANSIERI, 2012).

No Brasil, os direitos sociais, com destaque para o direito à moradia, se fundamentam no Princípio da Dignidade Humana (Art. 1, Inciso II, Constituição Federal de 1988), sendo vinculados aos objetivos fundamentais da República: construção de uma sociedade livre, justa e solidária; garantia do desenvolvimento social; erradicação da pobreza e marginalização; redução das desigualdades sociais e regionais; promoção do bem-estar de todos (Art. 3, Incisos I, II, III, IV, Constituição Federal de 1988) que constituem as bases do Estado brasileiro e visam garantir a reprodução da vida humana com dignidade de forma progressiva. (PANSIERI, 2012)

Sendo assim, a tutela da reprodução da vida humana com dignidade colocada na Constituição Federal de 1988 como dever do Estado viabiliza a igualdade-liberdade material dos indivíduos/cidadãos. Ademais, o autor afirma que os indivíduos somente serão livres quando estiverem inseridos na sociedade e participarem desta como atores reconhecidos e respeitados como cidadãos. Portanto, a falta de acesso aos bens mínimos como educação, saúde, moradia, dentre outros, atenta contra os fundamentos da República e deve ser enfrentado pelo Estado e a sociedade (ibidem).

Nesse sentido, a Constituição Federal de 1988 traz tanto a possibilidade de uma igualdade formal perante a lei, quanto os objetivos a serem alcançados pelo Estado na construção do Estado Social no qual todos os indivíduos participam, isto é, uma sociedade de indivíduos livres, portanto, cidadãos. Assim, o próprio sistema constitucional apresenta o sentido da dignidade e seus objetivos quando, por exemplo, trata dos direitos sociais educação, saúde, moradia, lazer, segurança, previdência, proteção aos desamparados. “A reprodução da vida humana é o fundamento ético-material do sistema constitucional e será alcançado quando toda a coletividade puder usufruir das possibilidades oferecidas pelos bens sociais postos à disposição pelo Estado" (PANSIERI, 2012, p. 15).

Nessa perspectiva, o direito à moradia encontra definição apropriada na Observação Geral n. 4 do Comitê de Direitos Econômicos, Sociais e Culturais da Organização das Nações Unidas (ONU, junho de 1993): “o direito à uma moradia adequada significa dispor de um lugar onde se possa asilar, caso o deseje, como espaço adequado, segurança, iluminação, ventilação, infraestrutura básica, todos a um custo razoável” (ONU citada por PANSIERI, 2012, p. 22). 
O autor alinha suas análises às Diretrizes da Comissão da Organização das Nações Unidas para Direitos Econômicos, Sociais e Culturais que identificou elementos básicos a serem atendidos no direito à moradia:

a) Segurança jurídica da posse, independentemente de sua natureza e origem;

b) Disponibilidade de infraestrutura básica para a garantia da saúde, segurança, conforto e nutrição dos titulares do direito (acesso à água potável, energia para o preparo da alimentação, iluminação, saneamento básico, etc.);

c) As despesas com a manutenção da moradia não podem comprometer a satisfação de outras necessidades básicas;

d) A moradia deve oferecer condições efetivas de habitabilidade, notadamente assegurando a segurança física de seus ocupantes;

e) Acesso em condições razoáveis à moradia, especialmente para os portadores de deficiência;

f) A moradia e o modo de sua construção devem respeitar expressar a identidade e diversidade cultural da população.

A seguir, o autor analisa diversos textos Constitucionais no Brasil que abordam, direta ou indiretamente, a moradia (PANSIERI, 2012, p. 22-23):

a) Constituição de 1891 - mencionava pela primeira vez que a casa é asilo inviolável, só podendo adentrar com autorização do morador, dispositivo ainda presente nos demais textos constitucionais brasileiros;

b) Constituição de 1934 - surgia pela primeira vez a ideia da busca por um benefício coletivo com relação à propriedade, tal concepção foi mantida nas Constituições de 1937 e 1946;

c) Constituição de 1946 - no Inciso 16 do artigo 141 prescrevia-se: "é garantido o direito de propriedade, salvo em caso de desapropriação por necessidade ou utilidade pública, ou por interesse social [...]"; esta também estava prevista no artigo 147 desta carta: “o uso da propriedade será condicionado ao bem-estar social".

d) Constituição de 1967 - trazia claramente a função social da propriedade com discreta menção à moradia. 
e) Constituição Federal de 1988 - fundada na dignidade da pessoa humana já atribuía à moradia um novo status expresso no texto em diversos dispositivos - artigo 7; artigo 23, Inciso IX; artigo 183.

Pansieri (2012) prossegue explicitando acerca do direito à moradia e sua vinculação à dignidade da pessoa humana - na Constituição Federal de 1988, no artigo 70, inciso IV, se prescreve como direito do trabalhador urbano e rural "um salário mínimo, fixado em lei, nacionalmente unificado, capaz de atender às suas necessidades vitais básicas e às de sua família com moradia"; no artigo 183 se prescreve: "aquele que possuir como sua, área de até duzentos e cinquenta metros quadrados, por cinco anos ininterruptamente e sem oposição, utilizando-a para sua moradia ou e de sua família adquirir-lhe-á o domínio"; também em outros institutos se atribui competência comum da União, dos Estados, do Distrito Federal e dos Municípios promoverem programas de construção de moradias e melhorias das condições habitacionais (Art. 23, Inciso IX, Constituição Federal de 1988).

O autor destaca ainda que foi com a Emenda Constitucional 26/00 que o direito à moradia foi elevado ao status de direito fundamental social, inserido no art. 6 @ da Constituição Federal de 1988:

\begin{abstract}
o núcleo básico do direito à moradia consiste no direito de viver com segurança, paz e dignidade, sendo necessário observar: segurança jurídica da posse; disponibilidade de serviços de infraestrutura; custo da moradia acessível; habitabilidade; acessibilidade; localização e adequação cultural. Assim, o conteúdo essencial do direito à moradia vinculado à dignidade da pessoa humana consiste em considerar parâmetros mínimos indispensáveis à uma vida saudável, à uma vida digna. Então, o direito à moradia é necessariamente o direito à uma moradia digna. (CONSTITUIÇÃO FEDERAL DE 1988, art. 6o citada por PANSIERI, 2012, p. 23).
\end{abstract}

No âmbito dessa Constituição o autor considera que se deva observar as normas sobre a política urbana nos artigos 182 e 183, bem como os artigos 188 e 191 referentes ao direito à moradia em áreas rurais; a proteção dos direitos culturais, nos artigos 215 e 216; a proteção à moradia das populações indígenas, no artigo 231; e o direito à moradia dos remanescentes das comunidades de quilombos, no artigo 68.

Por fim, Pansieri (2012, p. 24-25) identifica as normas relacionadas com o direito à moradia nas seguintes legislações brasileiras:

a) Estatuto da Cidade (Lei 120.257/ 2001);

b) Medida Provisória 2.220/2001 (concessão de uso especial para fins de moradia); 
c) Lei 8.245/1991 (locação de imóveis urbanos e formas de proteção dos moradores de cortiços);

d) Lei 6766/ 1919 e 9785/1999 (parcelamento urbano);

e) Lei 9636/1998 (Lei de Terras da União que trata da gestão e regularização dos imóveis de domínio da União);

f) Lei $4504 / 1964$ (Estatuto da Terra que trata do regime de posse e propriedade da terra);

g) Lei 6015/1973 (registros públicos);

h) Código Civil (Lei 10.406/2002 que trata do direito da família, herança, posse e propriedade);

i) Lei 10.840 de 11 de fevereiro de 2005 (que cria o Programa de Habitação Popular) e a Lei 11.124 de 16 de junho de 2005 que dispõe sobre o Sistema Nacional de Habitação de Interesse Social (SNHIS) que cria o Fundo Nacional de Habitação de Interesse Social (FNHIS) e institui o Conselho Gestor do FNHIS.

Após tratar do processo que se relaciona ao debate sobre o direito à moradia e as diversas ações para legitimá-lo e concretizá-lo, o autor reafirma que o direito à moradia deve ser entendido como correlato à dignidade da pessoa humana, isto é, o direito à moradia significa direito à moradia digna que se contrapõe à exclusão social, econômica, política e cultural ainda presente nas cidades.

\footnotetext{
Esta tutela da reprodução da vida humana com dignidade é disposta no texto constitucional como obrigação estatal que possibilita a igualdade-liberdade material na qual será livre aquele indivíduo que participa da sociedade, aquele que pode estar inserido como ator desta. Assim, quem não participa, não tem acesso aos bens sociais mínimos como saúde, educação, lazer, moradia, dentre outros, não será considerado um cidadão livre (PANSIERI, 2012, p. 185).
}

Na sequência será abordada a especificidade desse debate acerca do direito à moradia no âmbito do Serviço Social visando contribuir com a reflexão e a prática profissional do (a) assistente social nessa expressão da questão social (IAMAMOTO, 1998).

\section{Questão habitacional e intervenção do Serviço Social}

$\mathrm{Na}$ contemporaneidade, o Estado capitalista se caracteriza pelo avanço da programática neoliberal (com viés ultraconservador) priorizando os interesses das empresas 
privadas e investidores financeiros em detrimento da reprodução social dos trabalhadores. Tal quadro tem resultado na crescente precariedade das relações de trabalho, associada ao desemprego estrutural e ao desmonte das políticas sociais públicas, com a redução drástica de recursos estatais pautada numa lógica setorizada e focalizada, bem como o ataque aos direitos trabalhistas e sociais (conquistados em lutas históricas e democráticas) agravando profundamente as condições de vida da grande maioria da população (BEHRING; BOSCHETTI, 2007; SANTANA, 2018).

No que concerne à prática profissional do (a) assistente social esta se insere diretamente nas expressões da questão social (IAMAMOTO, 1998) visando a formulação e implementação de propostas através das políticas sociais públicas, dentre elas, a políticas urbana e de habitação objetivando o desenvolvimento urbano e o acesso à moradia e à cidade sustentável como um direito de cidadania e dever do Estado, preconizado pela Constituição Federal de 1988, pelo Estatuto da Cidade (2001) e pelo CFESS (2016).

$\mathrm{Na}$ atualidade esta atuação profissional na área da habitação se situa na perspectiva do direito à cidade (CFESS, 2016), tendo como desafio decifrar as contradições na realidade e construir práticas criativas capazes de superar as dificuldades encontradas pela população no seu cotidiano, tais como: precariedade ou falta de moradias; falta de acesso às políticas sociais públicas e aos equipamentos/serviços públicos; exposição às áreas de risco e insalubres; exposição a condições ambientais inadequadas; ausência de participação popular na gestão das cidades.

Nessa direção, o (a) assistente social atua visando contribuir com a efetivação do direito à cidade nos espaços de planejamento (formulação, gestão, execução e avaliação) à frente de ações em programas e projetos sociais, bem como no seu monitoramento via conselhos, órgãos públicos, organizações não governamentais, movimentos sociais que configuram espaços diversos de lutas objetivando a superação da desigualdade, do autoritarismo e do conservadorismo (CFESS, 2016).

Cabe destacar que as demandas para o Serviço Social na área da habitação no interior das instituições se constituem, com frequência: em situações emergenciais de alagamentos, deslizamentos, incêndios; na falta ou precariedade de moradias; nas condições irregulares de moradia; na urbanização; na regularização fundiária; na realocação de famílias de áreas consideradas inadequadas, de risco físico ou social; na inserção de segmentos sociais em programas, projetos, serviços e benefícios; em ações socioeducativas; na elaboração, 
implementação e avaliação de pesquisas, projetos, levantamentos socioeconômicos; entrevistas; atendimentos individuais e em grupos; realização de oficinas, de cadastros, dinâmicas de grupos; na coordenação e organização de reuniões, assembleias, de eventos institucionais internos e externos; na capacitação técnica de gestores e equipe multiprofissional; na supervisão de estagiários (as) de Serviço Social; na elaboração de documentos diversos (relatórios, diários de campo, laudos); na mobilização de comunidades; na assessoria e na consultoria (CFESS, 2016).

Deve-se ressaltar ainda que as políticas sociais estão vinculadas ao contexto histórico, sociopolítico e econômico no qual se inserem e este tem se caracterizado, como referido, pela negação dos direitos fundamentais legitimados na Constituição Federal de 1988 na medida em que se privilegia o direito privado e os interesses do mercado em detrimento do atendimento das necessidades coletivas (BEHRING; BOSCHETTI, 2007).

Nesse contexto, os limites da ação profissional na política de habitação e na política urbana estão relacionados a questões estruturais que se refletem na falta de planejamento, na ausência de interesse político, no não estabelecimento de prioridades, no clientelismo, no conservadorismo, no descaso com os serviços públicos, na fragilização das políticas sociais, na diminuição drástica de recursos públicos e na precarização das relações de trabalho (CFESS, 2016).

Como a atuação profissional do (a) assistente social historicamente visa mudanças na realidade, a despeito de concepções e contextos diversos, torna-se necessário construir estratégias coletivas de enfrentamento das expressões da questão social que trazem demandas diversas e complexas para o Serviço Social.

Desse modo, constituem desafios contemporâneos para o (a) assistente social assumir esse trabalho como exercício de criação coletiva, alimentando as demandas populares por autonomia e controle social, na apropriação do espaço urbano e adensando a luta pelo direito à cidade, criando condições de superação das dificuldades vivenciadas pela população através da construção de novas estratégias de intervenção e de articulação com as diferentes instâncias institucionais, com outros profissionais, com a sociedade civil organizada e com os usuários, visando a concretização da reforma urbana com a superação da exclusão e da segregação socioterritorial (CFESS, 2016). 
No que se refere à reflexão teórica sobre a produção da cidade e a desigualdade no acesso à habitação, Santana (2018) destaca que tem havido a incorporação desse tema no Serviço Social brasileiro. O Conselho Federal de Serviço Social (CFESS) vem contribuindo nesse debate acerca do tema trabalho profissional nas políticas urbanas, tendo publicado o documento Atuação de Assistentes Sociais na Política Urbana: subsídios para reflexão (2016). Nessa direção, autores clássicos e contemporâneos, de perspectiva crítica, têm sido fundamentais nos estudos acerca desse tema na área do Serviço Social, tais como: Engels (1975), Lefebvre (1999), Lojkine (1997), Harvey (2005), Topalov (1996), Maricato (2001), Santos (1993), expondo a histórica desigualdade social e econômica na apropriação do solo no modo de produção capitalista (SANTANA, 2018, p. 221).

No tocante ao espaço urbano deve-se salientar que a manifestação das expressões da questão social tem se acirrado devido à expansão do capital imobiliário que intensifica a lógica mercadológica do uso e ocupação da cidade, inviabilizando o acesso à moradia pelos trabalhadores em localidades dotadas de infraestrutura e com boa localização. Assim, verificase a configuração de uma cidade radicalmente desigual no acesso aos serviços públicos, o crescimento da violência urbana com o aumento de mortes de jovens negros e pobres pelo tráfico de drogas, pela milícia e a própria polícia. Também há a dificuldade de pagamento de taxas de serviços e impostos pelos moradores em áreas próximas aos empreendimentos imobiliários; perda de atividades laborais e pauperização de moradores reassentados ou remanejados por projetos urbanísticos (SANTANA, 2018; MARICATO, 2015; GOMES, 2015).

No trabalho desenvolvido pelos (as) profissionais de Serviço Social nessa área há a demanda pela sua atuação em projetos urbanísticos e habitacionais (para integrar equipes de trabalho social) visando, sobretudo, a remoção dos moradores de áreas consideradas de risco, insalubres ou alvo de interesses do mercado imobiliário e de empresas. Nesse aspecto, os (as) assistentes sociais têm sido desafiados numa atuação que, contraditoriamente, defende o direito à cidade (preconizado pelo projeto ético-político do Serviço Social) e, ao mesmo tempo, se vincula às demandas institucionais que priorizam os interesses do mercado imobiliário e minimizam direitos sociais (SANTANA, 2018; GOMES, 2015; CFESS, 2016).

Diante desse quadro, deve-se explicitar que a Associação Brasileira de Ensino e Pesquisa em Serviço Social (ABEPSS), o Conselho Federal de Serviço Social (CFESS) e a PósGraduação em Serviço Social no Brasil têm contribuído de modo significativo para a formação e a atuação dos (as) assistentes sociais em uma perspectiva crítica vinculada ao projeto ético- 
político do Serviço Social em diversas áreas, inclusive na questão urbana e habitacional (SANTANA, 2018).

No que se refere à questão urbana e habitacional as pesquisas têm abordado a intencionalidade de buscar a interpretação crítica acerca da apropriação privada do solo, inerente ao modo de produção capitalista, desvelando a desigualdade no uso da cidade pelas distintas frações de classes sociais. Ademais, o papel contraditório do Estado capitalista em atender, prioritariamente, às empresas capitalistas e, ao mesmo tempo, atender minimamente aos trabalhadores pauperizados das favelas, baixadas, que são os espaços possíveis (e inadequados) para a reprodução da ampla maioria da população (ibidem).

\footnotetext{
O espaço urbano é um lugar de luta de classes. Para o embelezamento das cidades para o capital, o Estado constitui um suporte essencial, disponibilizando vultosos recursos com infraestrutura urbana. Por esse motivo, vários trabalhos discutiram criticamente a mercantilização das cidades, os grandes eventos esportivos (como a Copa do Mundo e os Jogos Olímpicos), os grandes projetos de infraestrutura urbana [...], as remoções de moradores que passam por projetos de reassentamento ou remanejamento urbano, [...] a categoria de segregação socioespacial (SANTANA, 2018, p.232)
}

Destacam-se também os estudos sobre a precariedade habitacional (em pequenas cidades ou metrópoles), as contradições inerentes ao Programa Minha Casa, Minha Vida (PMCMV) que, apesar de ter contribuído para a redução do déficit habitacional, apresenta problemas no acesso aos serviços urbanos. Nesses estudos, são ressaltadas as condições das moradias, a inadequação na infraestrutura urbana nos espaços onde foram construídos os conjuntos habitacionais (ausência e /ou ineficiência de equipamentos urbanos, distância do centro, problemas com transporte, insegurança, etc.), ou seja, a questão da precariedade dos serviços urbanos que afeta a vida dos moradores atendidos por esse Programa, se soma às condições de pobreza e o alto nível de desemprego (SANTANA, 2018, p. 233).

Nesses estudos também se encontram reflexões sobre a atuação profissional do (a) assistente social, destacando-se os dilemas da profissão cuja intervenção é mediada tanto pelo projeto ético-político favorável aos trabalhadores, como pelos interesses capitalistas.

O dilema está em que os projetos urbanísticos, que movem os pobres e que requerem o trabalho profissional do assistente social, são envoltos no discurso de participação e organização comunitária, educação ambiental e geração de trabalho e renda, quando na verdade, em essência, trata-se do controle e manutenção dos pobres em lugares inadequados à moradia e em condições mínimas para exploração da força de trabalho" (SANTANA, 2018, p. 233). 
Nesse aspecto, há pesquisas que expõem as condições de vida da classe trabalhadora que passa por mudanças de moradias devido às intervenções urbanas do Estado. Assim, há estudos sobre a pós-ocupação, a avaliação de impactos socioeconômicos sobre a população que é remanejada, reassentada, mediante o PAC ou PMCMV. Além disso, as pesquisas abordam a organização política dos moradores na luta pela moradia, a questão da resistência social, a atuação de movimentos sociais, conflitos socioambientais, as contradições no acesso à cidade. $\mathrm{O}$ tema do direito à moradia e o direito à cidade nas pesquisas tem forte incidência, demonstrando a perspectiva crítica do projeto ético-político e sua articulação com as dimensões teórico-metodológicas, ético-políticas e técnico-operativas visando a edificação de uma sociabilidade para além do capital (SANTANA, 2018, p. 233-234).

A autora aponta que algumas pesquisas ressaltam as potencialidades da política de habitação de interesse social, como os planos locais de interesse social, os planos diretores, debatendo os desafios e possibilidades da atuação profissional na política urbana e habitacional. Nesse sentido, esse debate tem avançado no âmbito do Serviço Social, mas, ainda é necessário um maior aprofundamento do tema devido à sua complexidade e relevância (SANTANA, 2018).

No tocante à especificidade do trabalho do Serviço Social na remoção de moradores de favelas, na atual política urbana, Gomes (2015) considera que apesar de haver um conjunto de direitos e espaços de participação assegurados pela Constituição Federal de 1988, o quadro político e econômico tem contribuído decisivamente para esvaziar a dimensão política da profissão, para a instrumentalização da participação popular e o retorno de práticas conservadoras como a remoção compulsória de moradores de favelas. Portanto, a intervenção profissional no espaço urbano, especialmente nas favelas, tem demonstrado inflexões em termos de avanços na luta contra a desigualdade e na garantia dos direitos sociais.

Nesse contexto, a autora afirma que as novas formas de gestão urbana trazem implicações significativas no trabalho desenvolvido pelo (a) assistente social, destacando que existem distintas formas de inserção no trabalho realizado no espaço urbano. Em geral, o (a) assistente social integra equipes multiprofissionais que realizam o trabalho social, na medida em que esta não é uma prerrogativa do Serviço Social. E, com frequência, esse trabalho tem se efetivado no âmbito de empresas de arquitetura ou afins visando a subordinação do interesse público ao privado (GOMES, 2015). 


\begin{abstract}
"Ademais, esse tipo de inserção profissional se faz sob elevado grau de precarização das condições de trabalho e vulnerabilidade dos contratos de trabalho. Na realidade, o assistente social é um dos profissionais mobilizados na variedade enorme de especialistas convocados para um trabalho de controle social, visando deter a insatisfação dos segmentos populares que têm seus direitos violados ou não atendidos na cidade" (GOMES, 2015, p. 113).
\end{abstract}

\title{
Considerações Finais
}

O processo de urbanização capitalista, sobretudo, nos países do capitalismo periférico, tem se caracterizado historicamente pela deterioração das condições de vida da maioria da população que não consegue nem mesmo garantir sua reprodução física. Como esse processo visa a máxima obtenção de lucro, a aparente "desordem" do urbano não decorre de mero desequilíbrio, mas é produto da exigência de reprodução do capitalismo na sua periferia, ou seja, esta "desordem" é funcional ao capital. Tal processo tem impactado duramente amplos segmentos que não conseguem adquirir uma casa ou terreno dotados de infraestrutura e acesso aos serviços públicos no mercado formal. Como as terras urbanas se concentram nas mãos de grandes empresas e particulares para gerar o máximo lucro, a terra se transforma numa mercadoria especial constituindo o centro de interesse da reprodução da cidade fazendo com que esta urbanização concentracionista seja acrescida de uma dimensão segregacionista. Assim, diante dos altos aluguéis, do desemprego, da redução drástica de investimentos públicos nas políticas sociais, dentre elas a política habitacional, e a imposição de uma lógica mercadológica no acesso à moradia, a ampla maioria da população de baixa renda tem sido obrigada a recorrer a ocupações irregulares, em geral, em áreas periféricas da cidade que se caracterizam pela precariedade ou ausência de infraestrutura básica. É nesse quadro complexo e desafiador que se configura a questão habitacional (uma das expressões da questão social), sendo objeto da intervenção profissional do (a) assistente social (NICOLIS, 1996).

Deve-se salientar que a atuação profissional nessa área tem se pautado na perspectiva do projeto ético-político do Serviço Social visando efetivar o direito à cidade (CFESS, 2016). Com relação ao dilema apontado por Gomes (2015) e Santana (2018), acerca da incompatibilidade entre o projeto ético-político do Serviço Social que é favorável aos interesses da classe trabalhadora, e as demandas institucionais que priorizam a perspectiva do mercado e restringe direitos sociais, Baptista (2000) argumenta que tal situação não 
remete à redução da ação profissional aos limites institucionais, e, sim ao reconhecimento de que essa demanda pode potencializar a abertura de novos espaços de enfrentamento concreto da questão a ser trabalhada.

A autora afirma ainda que a polaridade entre instituição e usuários coloca muitas vezes um falso dilema ao profissional: atender à demanda tal como ela se apresenta, colocando-se ao lado do empregador; ou desenvolver trabalhos sintonizados com as demandas da população, colocando-se ao lado dos usuários. Este é um falso dilema por negar a contradição inerente à prática profissional dicotomizando a mesma. Na dinâmica contraditória entre as exigências da instituição e os requerimentos dos usuários, o dilema não está em optar por um dos lados, mas, em ter a capacidade de atender as demandas que são colocadas superando suas contradições. Isso não significa aceitar ou negar mecanicamente as demandas institucionais ou assumir inteiramente as demandas dos usuários. "Trata-se de reestruturar essa demanda, mediando interesses diversos, numa determinada direção éticopolítica, o que significa reconstruir o objeto da intervenção" (BAPTISTA, 2000, p.33).

Portanto, o (a) profissional de Serviço Social na sua prática vai perceber que nem sempre o objeto é rigidamente posto, nem os meios são totalmente limitados e, sobretudo, que os fins podem ser redefinidos. A demanda, o objeto, podem ser reelaborados para desenvolver um trabalho que valorize princípios ético-políticos que busquem superar a exclusão social, a discriminação e o não atendimento dos direitos sociais (BAPTISTA, 2000). Nesse sentido é que o debate crítico acerca do uso e ocupação do solo urbano e a função social da propriedade, preconizados na Constituição Federal de 1988, no Estatuto da Cidade (2001) e no CFESS (2016), torna-se imprescindível para subsidiar reflexões e intervenções concretas visando legitimar e efetivar o direito à cidade e, por conseguinte, o direito à moradia.

\section{Referências}

BAPTISTA, M. V. Planejamento Social: Intencionalidade e Instrumentação. 2a ed. São Paulo: Veras Editora, Lisboa: CPIHTS, 2000, p. 13-38.

BEHRING. E. R.; BOSCHETTI, I. Política Social: Fundamentos e História. São Paulo: Cortez, 2007. BRASIL. Constituição da República Federativa do Brasil de 1988. Brasília, DF: Senado Federal, 1988. 
BRASIL. Estatuto da Cidade. Lei n. 120.257 de 10 de julho de 2001. Brasília, DF: Ministério das Cidades, 2001.

CFESS, Conselho Federal de Serviço Social. Atuação de Assistentes Sociais na Política Urbana: subsídios para reflexão. Brasília, DF: CFESS, 2016 (Trabalho e Projeto Profissional nas Políticas Sociais, v. 5).

CORREA, R. L. O Espaço Urbano. 3ạ edição São Paulo: Ática S.A. (Série Princípios), 1995.

ENGELS, F. A Situação da Classe Trabalhadora na Inglaterra. Porto: Afrontamento, 1975.

GOMES, M. F. C. M. Serviço Social e Políticas Urbanas: entre o conservadorismo e a viabilização de direitos. Revista LIBERTAS. Faculdade de Serviço Social/ Universidade Federal de Juiz de Fora, Minas Gerais, Curso de Pós-Graduação em Serviço Social, v. 15, n. 2, p. 105-118, ago./dez. 2015.

HARVEY, D. A Produção Capitalista do Espaço. São Paulo: Annablume, 2005.

IAMAMOTO, M. V. O Serviço Social na Contemporaneidade: Trabalho e Formação Profissional. São Paulo: Cortez, 1998.

LEFEBVRE, H. A Cidade do Capital. Rio de Janeiro: DP\&A, 1999.

LOJKINE, J. O Estado Capitalista e a Questão Urbana. São Paulo: Martins Fontes, 1997.

MARICATO, E. Para entender a Crise Urbana. CaderNAU - Cadernos do Núcleo de Análises Urbanas - v.8, n.1, 2015, p. 11-22. Disponível em: periódicos.furg.br/cnau/article/viewFile/5518/3425. Acesso em: 24 jan. 2019.

MARICATO, E. Habitação e Cidade. 7ạ edição, São Paulo: Atual, 2010.

MARICATO, E. Autoconstrução, a Arquitetura Possível. In: MARICATO, E. (Org.). A Produção da Casa (e da Cidade) no Brasil Industrial. São Paulo: Alfa-Ômega, 1979, p. 71-93.

NICOLIS, F.C. A Luta pela Habitação Popular: Espaço de Atores Sociais. Rio de Janeiro. Dissertação de Mestrado: ESS/ UFRJ, 1996.

PANSIERI, F. Eficácia e Vinculação dos Direitos Sociais: Reflexões a Partir do Direito à Moradia. São Paulo: Saraiva, 2012, p. 13-40; 183-186.

SANTANA, J. V. Questão Urbana e Habitacional e Pós-Graduação em Serviço Social no Brasil. Serv. Soc. Rev. Londrina, v. 21, n.1, p. 217-238, jul./dez. 2018.

SANTOS, M. A Urbanização Brasileira. São Paulo: Hucitec, 1993. 
TOPALOV, C. Da Questão Social aos Problemas Urbanos: os reformadores e a população das metrópoles em princípios do século XX. In: RIBEIRO, L.C.Q.; PECHMAN, R. (Org.). Cidade, Povo e Nação: gênese do urbanismo moderno. Rio de Janeiro: Civilização Brasileira, 1996, p. 23-51. 